\title{
Análise postural em estudantes de uma escola pública de Viçosa, Minas Gerais
}

Joelma Barbosa Moreira, Léo Marques Soares de Freitas, Ana Carolina Lima Soares, Lucas Lopes Faraci, Matheus Nascimento, Karina Martinho

\section{Resumo}

Pesquisas apontam que várias complicações que possa interferir na postura surgem no período de maturação musculoesquelética, ou seja, na infância e adolescência, fase onde esses se encontram na escola, propiciando há adquirir maus hábitos que levam a alterar a sua postura. Avaliar as alterações posturais de escolares de uma escola pública de Viçosa-MG e relacionar com o uso correto da mochila e ocorrências de dor. Foi realizado um estudo estatístico descritivo do tipo transversal, em uma escola estadual de Viçosa - MG, composta por 36 alunos do $1^{\circ}$ ano do ensino médio com faixa etária de 15 a 18 anos, de ambos os gêneros, 19 meninas e 17 meninos, porém desses, apenas 24 aceitaram tirar as fotos para analise postural. Também foram coletados dados biológicos (idade e sexo). Para avaliação postural utilizou-se uma câmera fotográfica digital Fujifilm - FinePix S8200 e o programa Fisimetrix.V.2,5i para analise das imagens. Foi aplicado um questionário elaborado e utilizado o programa Stata que por meio do teste qui-quadrado de person, verificaram-se as associações entre as variáveis qualitativas e por meio do teste $\mathrm{T}$ compararam-se as médias das variáveis quantitativas. Verificou-se que dos 24 alunos, $63,16 \%$ que têm dor é do sexo e 41,18\% do sexo masculino. As alterações posturais encontradas foram: cabeça inclinada $(33,11 \%)$, pescoço inclinado a esquerda (65\%), ombro protuso $(66,67 \%)$, hipercifose torácica $(83,3 \%)$, lombar retificada $(37,5 \%)$ e hiperlordose $(37,5 \%)$. Quando relacionados com a dor, $65 \%$ apresentam inclinação à esquerda do pescoço e $68,75 \%$ ombro protuso, assim obtendo uma diferença significativa e, $46,15 \%$ cabeça inclinada, $55 \%$ hipercifose torácica, $77,78 \%$ hiperlordose lombar. A maioria carrega a mochila bilateralmente $(72.22 \%)$, e relacionando a dor, também apresentou uma diferença significativa. Observou-se que as alterações posturais estão relacionadas com o sexo, ocorrência de dor e a formar de carregar a mochila. A capacidade de generalização deste estudo torna-se limitada pelo tamanho da amostra e por não todos os estudantes terem aceitado tirar as fotos para analise postural, porém os resultados indicam a necessidade de realizações de ações preventivas e educacionais no ambiente escolar.

Descritores: Escolares; Alterações posturais; Mochila. 